Jurnal Populika

Volume 8, Nomer 1, Januari 2020

\title{
SOCIAL CLIMBER IDENTITY AND MEMORY : POTRET DIRI SEBAGAI OBJEKTIVITAS HIPERREALITAS KEHIDUPAN DAN DEGRADASI MEMORI
}

\author{
Nurfian Yudhistira \\ fianyudhistira@amikom.ac.id \\ Fakultas Ekonomi dan Sosial, Program Studi Ilmu Komunikasi, Universitas \\ AMIKOM Yogyakarta
}

\begin{abstract}
This study examines the development of photographic technology that facilitates the development of the phenomenon of social climbing by highlighting the hyperreality of social media, thereby resulting in the emergence of a new identity for social climbers. Photography technology has evolved over time. Digital technology has created instant technology that makes it easy for camera users to operate cameras with automatic adjustment features, therefore the technology industry is constantly looking for ways to develop and make smartphones. Smartphones integrate image and communication technology into one device, making it easier for users to communicate. This smart phone supports online access to social media because of its features that can be connected to the internet. So anyone can share their photography using this tool and also social media. social media makes it easy for everyone to access information including personal activities that are shared, so that phenomena that are often referred to as social climbing phenomena are phenomena marked by social media users who are competing to improve their social status on online social media. The phenomenon of social climbing makes someone create a new identity for themselves on social media. Creating a life that is exaggerated from its original reality or also called hyperreality. This study aims to provide education related to the use of photography and social media, so that people do not fall into the phenomenon of false identities in social media.
\end{abstract}

Keywords: photography technology, the phenomenon of social media trends, social media, hyperreality

\section{PENDAHULUAN}

Perkembangan teknologi fotografi bermula dari beralihnya fungsi litografi dengan media dan metode baru. sesuai yang dikatakan oleh Walter Benjamin dalam sebuah tulisannya yang berjudul "The World of Art in The Age of Mechanical Reproduction" (1935) yang membahas tentang makna reproduksi. Dalam tulisannya membahas tentang mekanisme perkembangan fotografi dan juga degradasi makna tentang seni. Lebih lanjut perkembangan fotografi semakin meluas. Darmawan (2002) mengatakan praktek fotografi pertama kali dikenalkan oleh AlHazen, AlHazen mempopulerkan kamera Obscura pada abad ke-11. Sejak kamera Obscura dipopulerkan, fotografi menjadi ramai digemari dan banyak dikembangkan. Pada era kerajaan Yunani, fotografi potret mulai diperdagangkan dalam bentuk dewadewa yang disembah, hingga potret untuk mempermudah pelukis agar tidak memajang modelnya berlama-lama, sehingga produk potret ini menjadi sebuah tradisi. Berikut adalah gambar sebagian perkembangan teknologi kamera: 


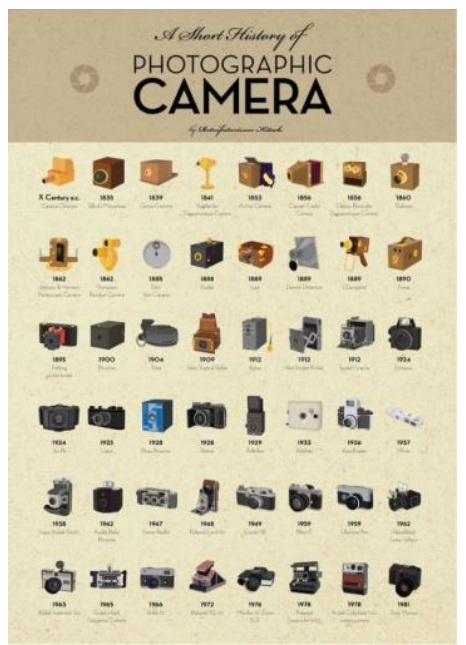

\section{Gambar 1. Perkembangan kamera Sumber : Kompas.com}

Gambar di atas menunjukkan bahwa perkembangan teknologi fotografi sangat signifikan, metamorfosa kamera juga berakibat pada metamorfosa teknologi, seperti halnya yang kita rasakan saat ini teknologi fotografi sangat memudahkan penggunanya untuk menciptakan gambar seperti yang diharapkan. Kemudahan teknologi fotografi juga mendorong perubahan perilaku manusia pengguna fotografi, menurut purwati (2015) dalam penelitian skripsinya mengatakan bahwa fenomena yang saat ini sangat marak terjadi di masyarakat adalah fenomena pendokumentasian kegiatan sehari-hari lalu membagikannya pada media sosial, media daring membuat semua orang mudah untuk mengakses informasi termasuk seperti kegiatan personal yang dibagikan tersebut, sehingga muncul sebuah fenomena yang kerap disebut dengan fenomena panjat sosial (Social Climber) yakni sebuah fenomena yang ditandai dengan para pengguna daring media sosial berlomba-lomba menaikkan status sosial mereka pada daring media sosial. Fenomena ini mempengaruhi banyak aspek dalam kehidupan para pemuda yang mengikuti trend fenomena tersebut. Seperti tren cara ngopi atau nongkrong, lifestyle, pola hidup remaja, tata bicara, bahasa, hingga perilaku keseharian

\section{METODE}

Penelitian ini membutuhkan metode untuk memperoleh hasil yang valid. Metode yang digunakan dalam penelitian ini adalah metode kualitatif, untuk mengumpulkan data lebih dalam dari narasumber terkait. Peneliti menjadi instrumen penelitian itu sendiri. Metode ini digunakan unutk menggambarkan aktivitas social climber pada media sosial yang mengunggah gambar dengan unsur hiperrealitas untuk menarik penyimak sosial media milik mereka. Penelitian kualitatif menurut Lincoln dalam Neuman (2003: 72) adalah penelitian yang menekankan pada proses dan pemaknaan atas realitas sosial yang tidak diuji atau diukur secara ketat dari segi kuantitas, ataupun frekuensi

\section{HASIL DAN PEMBAHASAN Industri Fotografi dan Perubahan Perilaku}

Fotografi memiliki dua fungsi, pertama sebagai media untuk merekam kenyataan dan kedua sebagai medium ekspresi artistik. Secara kodratnya sebagai alat perekam, fotografi memiliki hubungan yang dekat dengan keseharian dan perkembangan kehidupan sosial budaya dalam masyarakat. Ia memperlihatkan kehidupan urban atau pedesaan, kehidupan secara alami, modernitas, wajah orangorang, lanskap, kultur, fashion, kegembiraan, keindahan lingkungan, kesedihan, kehancuran, perang dan perubahan dalam masyarakat (Alwi, 2004). Teknologi fotografi berkembang seiring masa, mulai dari teknologi kamera analog hingga teknologi digital kamera handphone. Teknologi digital menciptakan teknologi instan yang mempermudah pengguna kamera untuk mengoperasikan kamera 
dengan fitur pengaturan otomatis, sehingga pengguna kamera tidak diwajibkan untuk belajar teknik fotografi. Dengan kata lain pengguna kamera dapat membuat gambar seperti yang mereka inginkan tanpa harus belajar dasar-dasar pengoperasian kamera. Tidak hanya itu, industri-industri teknologi terus menggali cara dalam pengembangan tersebut dan membuat smartphone. Smartphone mengintegrasi teknologi image yaitu dengan mengelaborasi teknologi image dan teknologi komunikasi menjadi satu perangkat, sehingga memudahkan penggunanya dalam berkomunikasi. Dalam smartphone ini mendukung akses daring media sosial karena fiturnya yang dapat terhubung dengan internet. Sehingga siapapun dapat membagikan hasil fotografi menggunakan perangkat ini dan juga daring media sosial.

Perkembangan media sosial yang terus diakses oleh penduduk Indonesia akhirnya memunculkan fenomena sosial tersendiri yang disebut dengan cyberculture. Arti cyberculture secara harfiah dapat diterjemahkan sebagai budaya cyber. Dengan kata lain cyberculture adalah segala budaya yang telah atau sedang muncul dari penggunaan jaringan komputer untuk komunikasi, hiburan, dan bisnis. Cyberculture juga mencakup tentang studi berbagai fenomena sosial yang berkaitan dengan internet dan bentuk-bentuk baru komunikasi jaringan lainnya seperti komunitas online, game multiplayer online, jejaring sosial, texting, dan segala hal yang berkaitan dengan identitas, privasi, dan pembentukan jaringan (Bell, 2001). Di dalam cyberculture terdapat interaksi antara manusia yang satu dengan manusia yang lain khususnya dalam hal komunikasi dalam aspek visual. Cyberspace memberi ruang yang bebas bagi tiap individu untuk melakukan tindakan apa pun. Hal ini dapat dilihat dalam masyarakat urban yang memiliki kecanggihan teknologi dalam smartphone yang mereka gunakan di kehidupan sehari-hari.

Menurut Jean Baudrillard dalam bukunya simulacra and simulations (2002), hiperrealitas adalah konsep konstruksi sebuah realitas baru dengan menggunakan simbol-simbol untuk memanipulasi realitas aslinya dengan melampaui realitas asli. Sosial media dalam hal ini merupakan tempat terjadinya proses simulasi berlangsung. Manusia didalam pascamodern ini menjadikan sosial media sebagai acuan dari kehidupan nyata. Sehingga apa yang ada pada social media dianggap sebagai hal yang nyata. Hiperrealitas menghadirkan representasi sebuah kenyataan yang kebenarannya tidak dapat dipisahkan dengan rekayasa, berisi sebuah pesan yang menyampaikan kesan hiperbola terhadap realitas yang ada. Hiperrealitas menjadikan dunia riil atau nyata berkolaborasi dengan dunia fantasi. Hiperrealitas membuat orang akhirnya terjebak pada simulacra, dan bukan pada sesuatu yang nyata. Dalam konteks ini akan membicarakan tentang hiperrealitas yang ada di media sosial yang berkaitan dengan kamera, hiperrealitas dalam konteks gambar atau video. Tren mengunggah foto mulai menjamur, salah satunya adalah foto makanan. Tren mengunggah foto makanan ini mulai muncul beberapa tahun belakangan. Akhir-akhir ini jika berkunjung ke suatu tempat makan, pemandangan sekelompok orang yang memfoto makanan pesanannya sebelum dimakan tentu tidak asing lagi. Tidak ketinggalan, foto tersebut langsung diunggah ke media sosial dan menunggu respon kekaguman dari dunia maya. Tak jarang, ada juga orang yang meluangkan waktu dan biaya untuk pergi ke restaurant mahal dan memesan makanan istimewa demi ikut serta dalam tren ini (Fitria, 2015: 88). Terjadi perubahan pandangan, makanan yang tadinya untuk mengisi perut kini menjadi tanda (Sarup, 
2003: 287) yang ingin diperlihatkan kepada publik di media sosial.

Kehidupan sosial kerap sekali dihadirkan dalam bentuk image yang kemudian disajikan pada media sosial dengan berbagai keterangan. Mereka mendokumentasikan kehidupan mereka dengan mengunggahnya di media sosial dalam bentuk budaya selfie. Budaya swafoto atau selfie telah menjamur, setiap orang yang memiliki smartphone dapat melakukan kegiatan swafoto. Selfie adalah singkatan dari self portrait, yang artinya foto yang diambil dari kamera handphone atau kamera digital oleh orang itu sendiri. Mereka yang suka selfie ini menyebarkan hasil dari foto mereka ke media sosial, seperti Facebook, Twitter, dan instagram. Karena memang saat ini, media sosial banyak menyediakan media/aplikasi yang memang menggaet masyarakat untuk menyukai selfie dan narsis. Selfie biasanya digunakan untuk mengambil pose kasual dengan menggunakan kamera yang diarahkan pada diri sendiri. Selfie juga digunakan sebagai sebuah ajang dalam konteks aktualisasi diri secara visual, hal ini menunjukan bagaimana seseorang dapat menunjukkan eksistensi dirinya melalui visual. Bahkan demi mendukung eksistensi ini, perusahaan smartphone menciptakan fitur filter kamera yang berfungsi untuk menambah estetika pada visual pengguna kamera smartphonenya, hal ini membantu merealisasikan keinginan mereka yang belum terpenuhi dan membuat seseorang menjadi lebih percaya diri dalam menampilkan visualisasi diri mereka. Sehingga pada saat ini orang akan melihat fitur kamera apa saja yang ditawarkan oleh smartphone yang akan dipilihnya. Dari adanya budaya selfie, konsep hiperrealis ini juga berkembang pada perubahan perilaku seseorang di media sosial yang berakibat munculnya fenomena panjat sosial (Social Climber). Media sosial menjadi ruang terbaik hiperrealitas, karena dapat merepresentasikan hiperrealitas menjadi realitas palsu (Sarup, 2003: 293). Simulasi membunuh makna secara absolut dan memunculkan suatu kondisi hiperrealitas (Baudrillard dalam Ritzer, 2003: 162-163). Simulasi membuat realitas menjadi kabur. Oleh karena itu telah terjadi pengaburan kelas, dimana tidak adanya kejelasan dari kelas sosial yang dimunculkan di media sosial. Media sosial saat ini tidaklah lagi menampilkan realitas yang sebenarnya, namun menampilkan hiperrealitas (Ritzer, 2003: 163). Citra atau realitas buatan yang dibangun oleh media sosial berhasil menutupi realitas yang sebenarnya dan membentuk hiperrealitas. Media sosial saat saat ini melakukan simulasi, manipulasi, rekayasa dan mengubah bentuknya sendiri menjadi pesan itu sendiri.

\section{Fenomena panjat sosial (Social Climber) dan Degradasi memori}

Menurut Pradhana (2019) Panjat Sosial atau bisa disebut dengan Social Climbing yakni sebuah istilah yang menyatakan perbuatan seseorang yang memanfaatkan orang lain, barang, ataupun peristiwa untuk mendapatkan perhatian, memperoleh keuntungan tertentu, ataupun meningkatkan status sosial. Fenomena ini terjadi sebagai sebuah self presenting dengan menggunakan alat dokumentasi dan juga media sosial, media sosial yang ramai digunakan unutk panjat sosial adalah instagram dan facebook. Menurut Goffman (1959) Self Presenting atau presentasi diri sering juga disebut sebagai manajemen impresi (impression management) merupakan sebuah tindakan menampilkan diri yang dilakukan oleh setiap individu untuk mencapai sebuah citra diri yang diharapkan dan biasanya merupakan citra yang positif.

Media sosial instagram memiliki fitur instastory yang kerap digunakan unutk 
membagikan kegiatan personal seseorang pada pengikutnya. Dari hal itulah pengikut kemudian dapat membandingkan dirinya dengan orang yang dilihatnya dalam media sosial, kemudian timbulah rasa ingin menyamakan kehidupannya dengan kehidupan orang yang di ikutinya. Cara yang ditempuhpun bermacam-macam, seperti berteman dengan orang yang memiliki latar belakang ekonomi yang berlebih atau memiliki popularitas yang tinggi kemudian mendokumentasikannya dan membagikan pada media sosial agar mendapat perhatian dari orang lain. Dalam sebuah wawancara dengan seorang mahasiswa salah satu universitas di Yogyakarta dengan inisial PN (2019) mengatakan bahwa "aku ke cafe cuma mau update instastory saja, kadang nggak pesan minuman, hanya nebeng minuman teman. Supaya pengikut instagramku mengira hidupku selalu bahagia, selalu berkecukupan, padahal pada kenyataannya tidak".

Lebih lanjut, argumen tersebut juga dikuatkan oleh seorang mahasiswi Universitas Muhamadiyah Yogyakarta dengan inisial FP (2019) dalam sebuah wawancara yakni "aku liburan nggak pernah bayar atau punya uang, aku nebeng temantemanku yang bernotabene anak konglomerat, dan Cuma sekedar pengen update instastory aja supaya dikira ekonomiku sama dengan teman-teman sepergaulanku."

Salah satu pelayan pada sebuah cafe di Yogyakarta dengan inisial YK dalam sebuah wawancara (2020) juga mengatakan bahwa " aku biasanya update Igs (instagramstory) di meja bar cafe, selama ini teman-temanku mengira aku barista padahal aku pelayan biasa. Tapi aku senang pegikut instagramku tidak tahu kehidupan asliku, kehidupan yang mereka (pengikut instagram) tahu pada media sosialku adalah kehidupan impianku, bukan kehidupan asliku."

Berdasarkan data di atas, seringkali fenomena panjat sosial ini menuntut penganutnya untuk membuat identitas baru pada dunia maya yang berbeda dengan identitas aslinya pada dunia nyata. Kehadiran media sosial di kalangan remaja, membuat ruang privat seseorang melebur dengan ruang publik. Terjadi pergeseran budaya, sebagian orang kini tidak segansegan mengupload segala kegiatan pribadinya untuk disampaikan kepada teman-temannya melalui akun media sosial dalam membentuk identitas diri mereka. Identitas, merupakan sebuah hal yang penting di dalam suatu masyarakat yang memiliki banyak anggota. Identitas membuat suatu gambaran mengenai seseorang, melalui; penampilan fisik, ciri ras, warna kulit, bahasa yang digunakan, penilaian diri, dan faktor persepsi yang lain, yang semuanya digunakan dalam mengkonstruksi identitas budaya. Identitas menurut Klap (Pradhana, 2019) meliputi segala hal pada seseorang yang dapat menyatakan secara sah dan dapat dipercaya tentang dirinya sendiri - statusnya, nama, kepribadian, dan masa lalunya. Social Identity Theory (SIT) menurut Tajfel \& Turner (Pradhana, 2019) dalam bertujuan bahwa individu memiliki sebuah konsep pada dirinya sendiri dalam bersosialisasi dan mengidentifikasi dirinya sendiri. Fenomena panjat sosial mengandung hiperrealis yang dapat membentuk sebuah identitas baru, sehingga identitas seseorang dapat menjadi bias antara identitas secara riil dan identitas yang dibentuk dalam dunia maya, terkadang dapat membuat seseorang lupa akan dirinya pada dunia nyata karena sibuk unutk membentuk identitas barunya dan bermain dengan identitas barunya pada dunia maya.

Menurut Hollingworth (2005), media memiliki dampak dalam pembentukan 
memori jangka panjang ${ }^{1}$ seperti Media mengganggu pengalaman karena mendorong multitasking, Media membuat seseorang dapat mengeksternalisasi pengalaman, Media dapat menyimpan pengalaman seseorang, Media sosial membuat seseorang dapat membagikan pengalaman pada orang lain. terjadi Ketika media di elaborasikan dengan hiperrealis maka akan terjadi sebuah pendistorsian ingatan seseorang, hal yang seharusnya tidak ada akan menjadi ada dan sebaliknya. Seseorang akan mencipatakan sejarah yang manipulatif karena adanya degradasi memori yang diakibatkan oleh hiperrealitas.

\section{Daftar Pustaka}

Alwi, A. M. (2004). Foto Jurnalistik (Metode Memotret dan Mengirim Foto ke Media Massa). Jakarta: Bumi Aksara.

Bell, D. (2001). An Introduction to Cybercultures. New York: Routledge.

Baudrillards. J. (2002). Simulacra and Simulation. Ann Arbor The University of Michigan Press.

Goffman, E. (1959). The Presentation of Self in Everyday Life, Harmondworth: Penguin.

Hollingworth. A. and Luck. S.J (2005). Visual Memory. Oxford University Press.

Neuman. W Lawrence. 2006. Social Research Methods Sixth Edition. Boston: Allyn and Bacon.

Pradhana. T.A. (2019). Self-Presenting Pada Media Sosial Instagram Dalam Tinjauan Teori Dramaturgi Erving
Goffman. Skripsi Universitas Islam Negri Sunan Ampel. Surabaya

Ritzer, G. (2003). Teori Sosial Postmodern. Yogyakarta: Kreasi Wacana.

Sarup, M. (2003). Panduan Pengantar untuk Memahami Poststrukturalisme dan Posmodernisme. Yogyakarta: Penerbit Jendela.

\section{Wawancara}

FP. (2019). Wawancara dilaksanakan di perumahan jambusari, candi gebang Yogyakarta pada pukul 09.00 WIB

PN. (2019). Wawancara dilaksanakan di cafe Estuary pada 12 November 2019 pukul 19.50 WIB

YK. (2020). Wawancara dilaksanakan di café Alembana pada 2 januari 2020 pukul 21,15 WIB.

\footnotetext{
${ }^{1}$ Lebih lanjut baca Hollingworth. A. and Luck. S.J (2005) Visual Memory. Oxford University Press.
} 